\title{
The Determination of Hydraulic Motor Displacement
}

\author{
Paul Michael ${ }^{1}$, and Jose Garcia-Bravo ${ }^{2}$ \\ ${ }^{1}$ Fluid Power Institute, Milwaukee School of Engineering, Milwaukee, WI. United States \\ E-mail:michael@msoe.edu \\ ${ }^{2}$ School of Engineering Technology, Purdue University, West Lafayette, IN. United States \\ E-mail: jmgarcia@purdue.edu
}

\begin{abstract}
Because the geometrical displacement of a pump or motor is very difficult to measure directly, the derived capacity of motors is used to assess the efficiency of positive displacement machines. The current internationally accepted method for deriving the displacement of hydraulic pumps and motors is ISO 8426:2008. Difficulties in accurately assessing derived displacement via ISO 8426:2008 have been reported by several authors. These inaccuracies can lead to efficiency results that exceed $100 \%$ in ISO 4409:2019 performance tests. In the presented work, fixed axial, variable axial, and radial piston motors were evaluated at $50^{\circ} \mathrm{C}$ and $80^{\circ} \mathrm{C}$ in dynamometer tests. Linear, orthogonal, and semi-randomized data sets were collected. The Wilson, Toet, and an analytical form of the Toet were compared with ISO 8426:2008. In general, the differences between the various methods for deriving displacement were not statistically significant, except in the instance of the axial piston motor. In the axial piston motor, the ISO 8426:2008 derived displacement was approximately 1\% lower than the other methods. Use of this lower ISO 8426:2008 displacement in efficiency calculations produced values exceeding 100\%. The error in the ISO 8426:2008 derived displacement determination was attributed to difficulties in detecting speeddependent factors that affect displacement when testing is conducted at a single speed. The ISO 8426:2008 method does not provide instructions for calculating derived displacement when data is collected at more than one speed. It is proposed that the One-Step Toet method be incorporated into ISO 8426 as a method for calculating the derived displacement when users opt to measure performance at multiple speeds. This revision will reduce the potential for speed-dependent errors in the determination of derived displacement.
\end{abstract}

Keywords: Hydraulic Components, Efficiency, Test methods. 


\section{Introduction}

Hydraulic fluid power is used in a wide range of industries including transportation, construction, mining, agriculture, the production of basic metals, and manufacturing. In a typical fluid power system, the mechanical energy of an electric motor or internal combustion engine is transferred to the fluid medium by a positive displacement pump and the controlled motion of the fluid is used to actuate valves, cylinders, and hydraulic motors. Flow and pressure losses due to internal leakage, fluid compressibility, and friction can compromise the efficiency and productivity of fluid power systems. In a 2012 publication the US Department of Energy (DOE) estimated that an average of $21 \%$ of the input power from prime movers is converted to work by a typical fluid power system [1]. These findings have spurred improvements in hydraulic pump and motor efficiency. A thorough analysis of the current understanding of the efficiency of pumps and motors was carried out by Achten et at. [2] where the effect of the changes in the internal energy of the fluid due to the compressibility effect, was found to be a significant contributor to discrepancies found while estimating the hydromechanical and overall losses of a pump or a motor. These differences where demonstrated experimentally to be higher than $10 \%$ when compared to the traditional method proposed in ISO 4409. Likewise, Williams [3] devised a methodology for estimating the volumetric efficiency based on a hydraulic resistance model, such model lumped specific performance characteristics of the pump into a hydraulic parameter that could be used to evaluate the efficiency of the machine at various operating conditions.

Hydraulic motor efficiency is a critical factor in the design of off-highway machines because it affects the maximum vehicle payload and the top propulsion speed. Since motor output shaft speed and output torque are proportional to motor displacement, an accurate estimate of the amount of fluid displaced per machine revolution is necessary to model hydraulic system performance and assess component efficiency and dynamic performance. Conceptually, hydraulic pumps and motors are positive displacement machines and the volume of fluid transferred from component inlet to the outlet per revolution is assumed to be constant, unlike for instance a centrifugal pump or torque converter. In practice however, the displacement volume of positive displacement machines can be affected by pressure, speed, and fluid viscosity. While these changes may be relatively small, they introduce complexity into the determination of displacement volumes. In the following, several methods for sample selection and determination of derived displacement are experimentally investigated. This exploration is unique, insofar as it focuses on motors and the effect of temperature on motor displacement.

\section{Description of methods for determining displacement}

\subsection{Geometric displacement}

The most basic method for determining the volume displacement of a machine is to measure the volume of fluid it takes to fill cylinders using a burette or calculating it based upon dimensional drawings. The resulting geometric displacement $V_{g}$ is limited in accuracy because it does not account for changes in tolerances, clearances, and deformation that occur when the unit is operating [7]. In many cases this technique is impractical because it requires disassembly of the component. Determination of displacement without disassembly may be accomplished by measuring the volumetric flow per shaft revolution. Various methods for determining the volumetric flow per revolution have been discussed in earlier publications [8]-[10]. These methods define derived displacement as the volume displaced per revolution at zero differential pressure $(\Delta p=0)$. Based upon Newtonian physics, flow or displacement of fluid is not possible at $\Delta p=0$. Hence derived $\left(V_{i}\right)$ is conceptual and not a physical property of a component.

\subsection{ISO 8426:2008 method}

In the ISO 8426:2008 standard test method, the motor inlet flow rate is measured as a function of pressure at constant speed, temperature, and commanded displacement [11]. The derived displacement, $V_{i}$, is found by calculating the ratio of the actual flow $q_{v e}$ and the shaft speed $N$ at each measured pressure. The flow volume per revolution is plotted as a function of pressure and the zero intercept, that is, when $\Delta p$ is equal to zero, and it is determined via linear regression. The value of $V_{i}$ is defined to be the zero-pressure intercept of the line as shown in fig. 1. The key parameter that is measured in the determination of derived displacement is the flow rate. Since flow depends upon speed in a positive displacement machine, limiting the data set to a single speed produces a very narrow range of flow measurements. The narrow range of the sample set amplifies small errors in the flow measurements and neglects the effects of speed-dependent forces and cross-port leakage on displacement. Thus the use of ISO 8426:2008 displacements in ISO 4409:2019 performance tests occasionally produces efficiency values that exceed $100 \%$ [4]-[6]. Alternative methods for determining the derived displacement are presented below. 

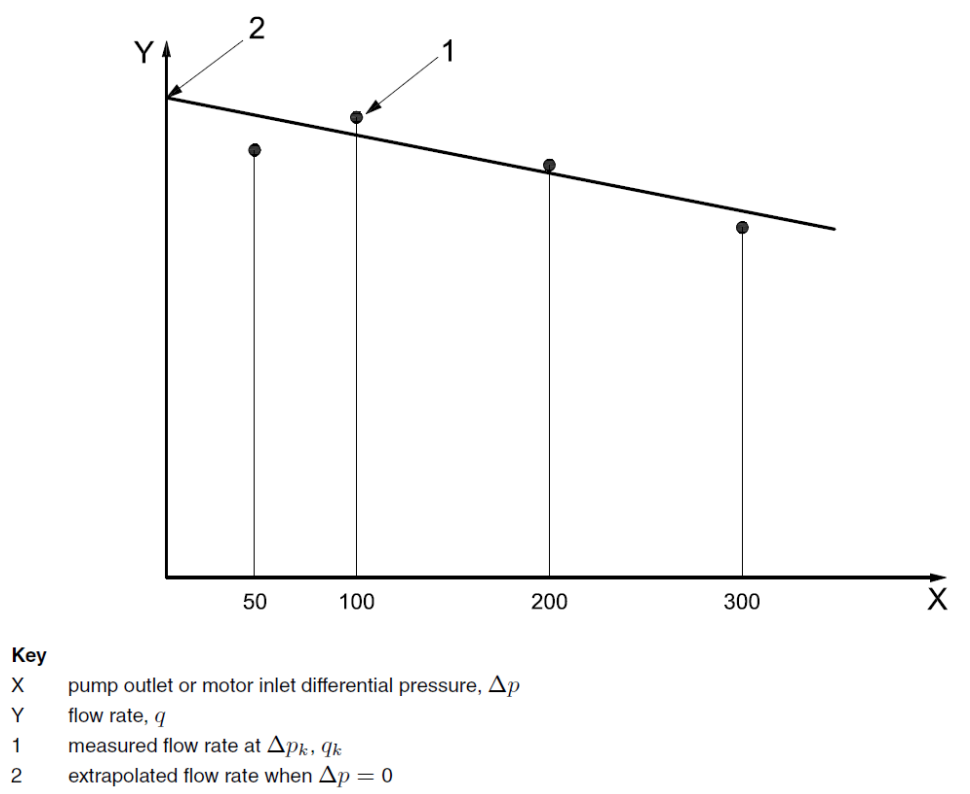

Figure 1: Graphical representation of the ISO 8426 method for deriving the displacement of a hydraulic pump [11].

\subsection{Toet two-step graphical method}

The Toet method was first introduced in 1970 [9], and it investigated the effects of shaft speed on the delivery of a pump at various pressures. In an ideal positive displacement machine, inlet and outlet flow rates are unaffected by pressure. However, gaps are required between moving surfaces within the pressure envelope to create a wearand friction-reducing lubrication film. These gaps provide a path for pressure-driven leakage flow within a pump or motor. Due to pressure-driven and compressibility flow losses, the delivery of a positive displacement machine is not exactly coincident with its geometrical displacement. Furthermore, Toet explicitly discussed how the delivery of a positive displacement machine is affected by changes in pressure and temperature. The Toet method, which was produced after studying the behavior of 200 pumps, postulated that because the relationship between the effective volumetric flow rate and the shaft speed are highly linear, the derivative of flow with respect shaft speed should be constant. Thus, the Toet method calls for the measurement of effective flow rate at a minimum of five different shafts speeds. These measurements are to be repeated at different pressure levels under constant temperature conditions. For each pressure case a fitted line between effective flow and shaft speed is graphically determined and the slope of the line is obtained. The second step of the method calls for a fit of a line through the data relating the previously obtained slopes to the measured pressure. The zero-intercept of this second line corresponds to the derived displacement of the positive displacement machine according to Toet.

\subsection{Wilson method}

The Wilson method [8] resembles the Toet method but differs in the definition of the procedure to estimate the derived capacity of a positive displacement machine. In the first step of the Wilson method, linear relationships between the effective flow rate versus pressure are established at various shaft speeds. The intercepts of the various lines at zero pressure are then used in the second step to produce a linear relationship between the effective flow rate and the shaft speed. The slope of the resulting line from the second step corresponds to the derived capacity. According to Post [10] the two methods, Toet and Wilson, produce comparable results. Post also concluded that the displacement of pumps and motors is not a constant value because it varies with pressure, temperature, and shaft speed.

\subsection{One-step Toet method}

Because the above-mentioned methods are based on experimental data, one can use a statistical procedure to fit said data to predict the flow output or input of a pump or motor. In the One-Step Toet method, all of the data is fitted to a line and one of the linear coefficients is used for determination of the derived displacement. The presented method is based on the original Toet procedure [9] and synthetized into a single analytical method that uses multiple linear regression to determine the displacement [12]. 
The One-step Toet method can be derived by recognizing that the flow model for a pump or motor can be described by a linear relationship between the pump or motor flow $q_{v_{e}}$ and the shaft speed $N$ (eq.1).

$$
q_{v_{e}}=V_{i} \cdot N
$$

Other variables of less influence may be considered as part of this relationship, as seen in [12], these may include temperature, viscosity, modulus of elasticity, bulk modulus of the fluid, etc. The constant of proportionality in the linear relationship accompanying the rotational speed of the pump or motor corresponds to the derived capacity $V_{i}$ of the hydrostatic machine.

Taking the partial derivative of the flow equation, eq. 1 above with respect to the shaft speed and assuming a different line at various pressures yield the expression shown in eq. 2 below:

$$
\left(\partial q_{v_{e}} / \partial N\right)_{p i}=m_{i}
$$

Where $m_{i}$ is the slope of the line. A family of lines can be generated to represent the slope of the flow versus shaft speed relationship shown in eq.1. This is known as the first step of the Toet method [9]. The second step of the method requires the calculation of the slope of the values generated from the first step with respect to the pressure values. Hence, a second partial derivative expression can be developed to represent the second step shown in eq. 3 below. Where $\beta_{3}$ corresponds to the slope of the line made from the various $m_{i}$ values obtained in step one. The expression for determining the flow may be obtained by integrating twice the partial derivative from eq. 3 . Assuming that the correspondence of the variables in the two previous partial derivatives is linear, one may say that the result from the derivative of a line is a constant value $\beta_{3}$.

$$
\frac{\partial\left(\frac{\partial q_{v_{e}}}{\partial N}\right)}{\partial p_{i}}=\beta_{3}
$$

Rearranging eq. 3 and integrating with respect to pressure, $p_{i}$ produces the expression:

$$
\frac{\partial q_{v_{e}}}{\partial N}=\beta_{3} p_{i}+\beta_{2}
$$

Where $\beta_{2}$ is an integration constant. Rearranging terms in eq. 4 and integrating a second time with respect to the shaft speed produces a linear flow equation as presented in eq.5.

$$
q_{v_{e}}=\beta_{3} p_{i} N+\beta_{2} N+\beta_{1} p_{i}+\beta_{0}
$$

The goal of the One-step Toet method is to fit the experimental data to a target function for the flow exiting or entering the pump or motor in the form presented in eq. 5. With the One-step Toet method, the experimental data used for fitting the flow model of eq. 5 is the same required for the two step Toet method, that is, the effective flow rate at various shaft speeds and at different pressure levels. The shaft speed coefficient, $\beta_{2}$ corresponds to the derived displacement of the component and has shown to yield the same value produced by the Toet graphical method as presented in section 4 below.

\subsection{Latin Hypercube Sampling (LHS)}

The ISO 8426:2008, Toet and Wilson methods for determining the derived displacement are based upon orthogonal sample plans. That is, each sample point is either in-line (ISO 8426:2008) or at a right angle (Toet and Wilson) to each other. Latin Hyperspace sampling (LHS) is a pseudo-randomized methodology for selecting experimental test points. It has been found to produce higher fidelity results than orthogonal methods in terms of identifying test points to populate empirical flow and torque models [13]. The scheme requires the test data to be acquired using an algorithm where the probability distribution of the variables to be measured is used to obtain the data points in a randomized way. In order to maximize sampling efficiency, none of the data points are orthogonal, in other words only one data point is collected for any given pressure or speed. Once the pseudo-randomized data points are captured, these values are fit using a multivariate linear regression algorithm like the one used for the One-step Toet method presented above. Similarly, the regression coefficient accompanying the shaft speed corresponds to the derived displacement. 


\section{Methods and materials}

The displacements of the three motors listed in tab. 1 below were evaluated in this study. These specific units were selected because they are representative of motors used in a variety of off-highway vehicle applications. Each motor was run-in according to manufacturer-specified conditions prior to testing in order to stabilize tribological conditions and efficiency. The radial piston motor is designed for low-speed high-torque duty and incorporates 8620 and 52100 steel elements to withstand high surface contact pressures. The fixed and variable displacement axial motors are designed for higher speed applications. The pistons are constructed of steel while piston slippers, valve plates and cylinder blocks incorporate alloys of copper to enhance lubrication and heat transfer.

Table 1: Test motor specifications

\begin{tabular}{llll}
\hline Motor type & $\begin{array}{l}\text { Radial } \\
\text { piston }\end{array}$ & $\begin{array}{l}\text { Axial } \\
\text { piston }\end{array}$ & $\begin{array}{l}\text { Variable } \\
\text { axial piston }\end{array}$ \\
\hline Nominal displacement, cc/rev & 213 & 100 & $45.2 / 135.6$ \\
Rated speed, RPM max & 570 & 3300 & 3200 \\
Rated pressure, Bar max & 400 & 420 & 450 \\
\hline
\end{tabular}

The displacement measurements of all three motors were collected using a dynamometer consisting of a pressurecompensated axial piston pump, twin Variable Frequency Drives (VFD), pressure, temperature, and torque transducers, and an 18-channel data acquisition system. The VFD controllers were programmed for semiautomatic testing. A simplified hydraulic circuit diagram is shown in fig. 2. A $93 \mathrm{~kW}$ electric load motor that was rated for a maximum speed of $1800 \mathrm{rpm}$ provided the resistive load. The axial and variable motors were not evaluated at their full rated speeds due to this limitation. Fifteen seconds of data were collected for each set point at a sampling rate of $100 \mathrm{~Hz}$. The input flow rate for each motor was measured at various speeds and pressures according to requirements for each derived displacement method. The results were compared using the twosample $t$ test at a $95 \%$ confidence interval $(\alpha=0.05)$ as described in Eq. 6.

$$
100 *(1-\propto) C I=V_{i} \pm\left(t_{n-(k-1), \propto / 2}\right) * S E_{\left(V_{i}\right)}
$$

The null hypothesis is that different methods produce the same derived displacement results $\left(H_{o}: V_{i j}=V_{i k}\right)$. When $95 \%$ confidence intervals for the derived displacement methods overlap, the $t$ test fails to reject the null hypothesis and the difference between the derived displacement results is said to be not statistically significant. The alternative hypothesis is the methods are not equal $\left(H_{a}: V_{i j} \neq V_{i k}\right)$. When the $t$ test rejects the null hypothesis, $H_{a}$ is accepted and the difference between the derived displacement results is said to be statistically significant.

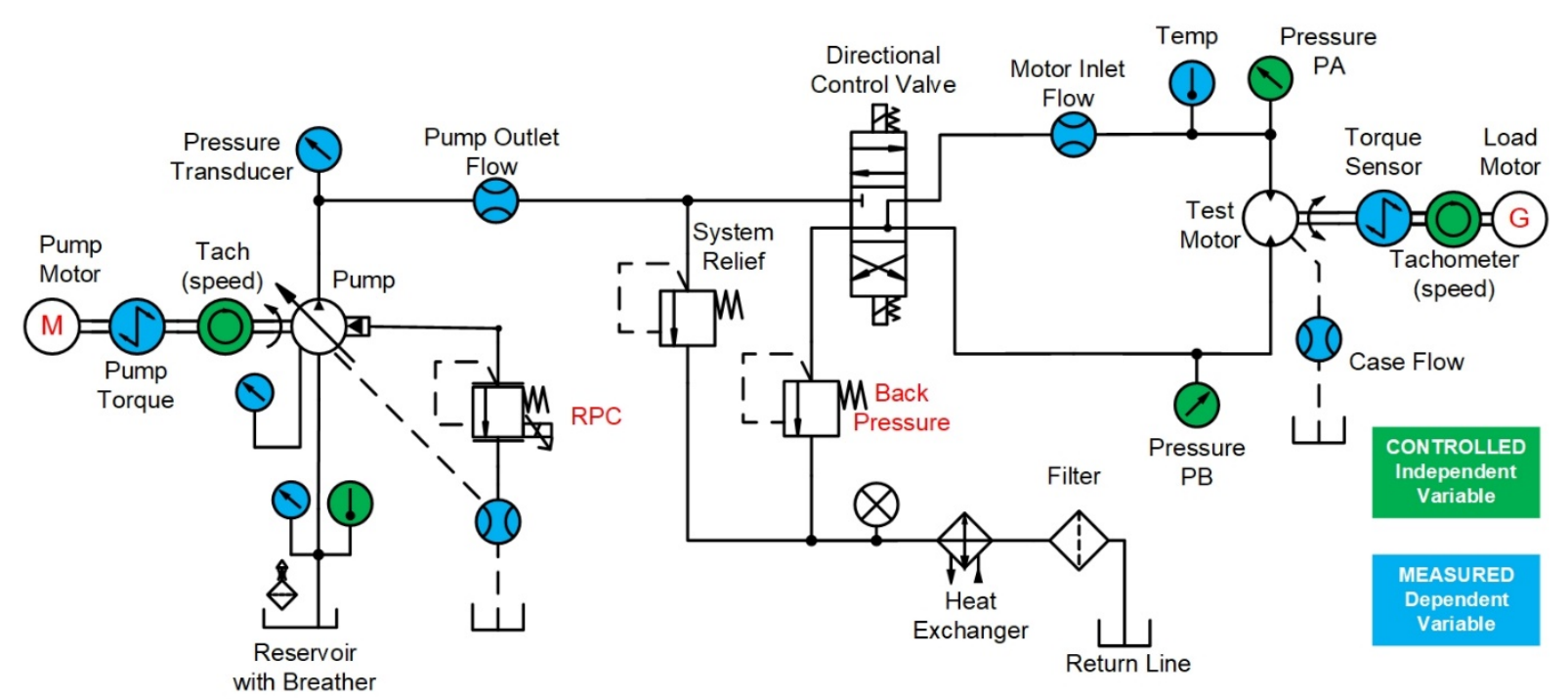

Figure 2: Hydraulic circuit schematic for motor derived displacement determinations. 


\section{Results and discussion}

According to ISO 4409:2019, "tests shall be carried out at a stated test fluid temperature. The test-fluid temperature shall be measured at the inlet port of the unit under test and be within the range recommended by the manufacturer. It is recommended that measurements are made at two temperature levels, $50^{\circ} \mathrm{C}$ and $80^{\circ} \mathrm{C}$." [15] The dynamometer testing below was conducted with the pump inlet temperature at $50 \pm 1^{\circ} \mathrm{C}$ and $80 \pm 1^{\circ} \mathrm{C}$. As in a normal hydraulic system, motor inlet temperatures tend to be several degrees higher due to the fluid temperature rise caused by the pump. As shown in fig. 3, the inlet mean temperature of the three motors was $1^{\circ} \mathrm{C}$ to $3{ }^{\circ} \mathrm{C}$ higher than the pump inlet temperature. ISO 8426 specifies that the temperature at the inlet of the test article be reported. In the discussion below, the pump inlet temperature is used to nominally describe the motor inlet temperature. The results reported in section 4.6 show that a $1^{\circ} \mathrm{C}$ to $3^{\circ} \mathrm{C}$ variation in temperatures is unlikely to produce a statistically significant change in the derived displacement.

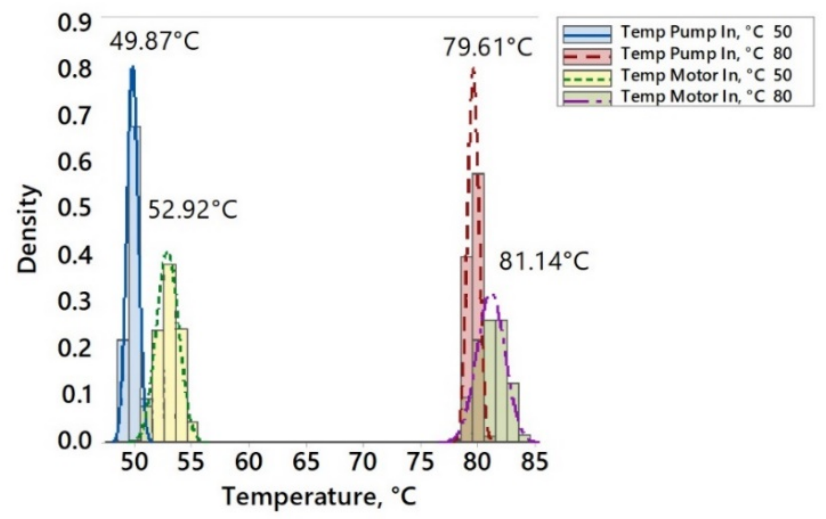

Figure 3: Histogram of the pump and motor inlet temperature measurements for the 3 test motors

\subsection{Axial piston motor}

The test plan for the axial piston motor is shown in fig. 4. The pressure ranged from 6.89 to $27.58 \mathrm{MPa}$ and the shaft speed ranged from 50 to 1285 RPM. The lower limit of the rotational frequency for the motor was established to ensure that the flow meter was operating well above the lower detection limit of the sensor. The ISO 8426:2008 method specifies that data for 10 or more test pressures must be collected in equal increments to achieve measurement accuracy class "A." Eleven measurements were collected between 6.89 and 27.58 MPa at 1000 RPM. Forty-five non-orthogonal data points were collected for the One-step Latin Hypercube method. Thirty-two orthogonal data points were collected for the Toet and Wilson methods (4 pressures and 8 speeds). Hence, a total of 89 data points was collected for the axial piston motor.

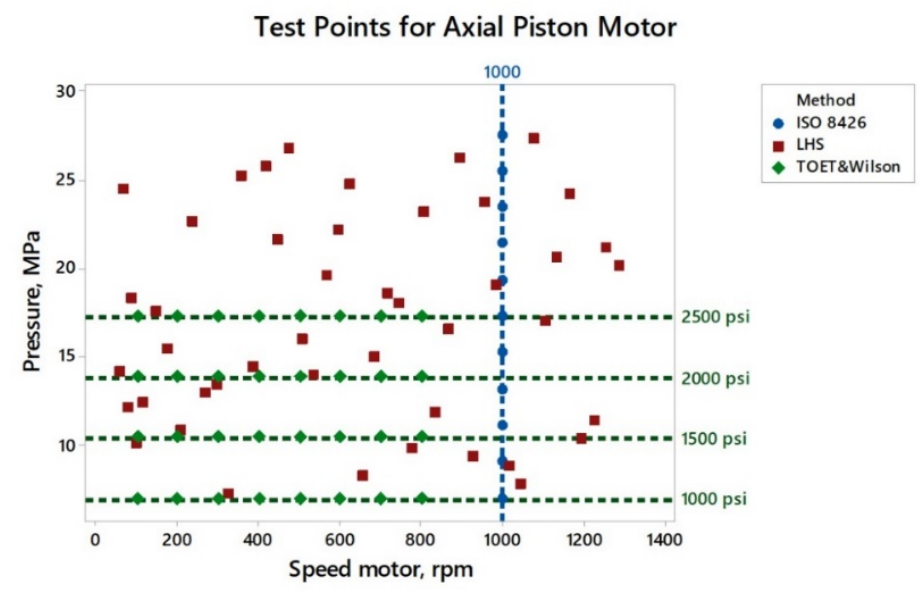

Figure 4: Test points for evaluating the derived displacement of the axial piston motor via ISO 8426, Toet, Wilson, and Latin Hypercube methods. 
The results for the estimation of the derived displacement using the graphical Toet method are shown in fig. 5 and fig. 6 below. The flow rate versus speed plot in fig. 5 shows that the results overlap at the 4 test pressures. As can be seen from the regression equations in the figure, the slope is highest for the $6.89 \mathrm{MPa}(1000$ psi) results. Hence the effective displacement per revolution was highest at the lowest pressure, as expected.

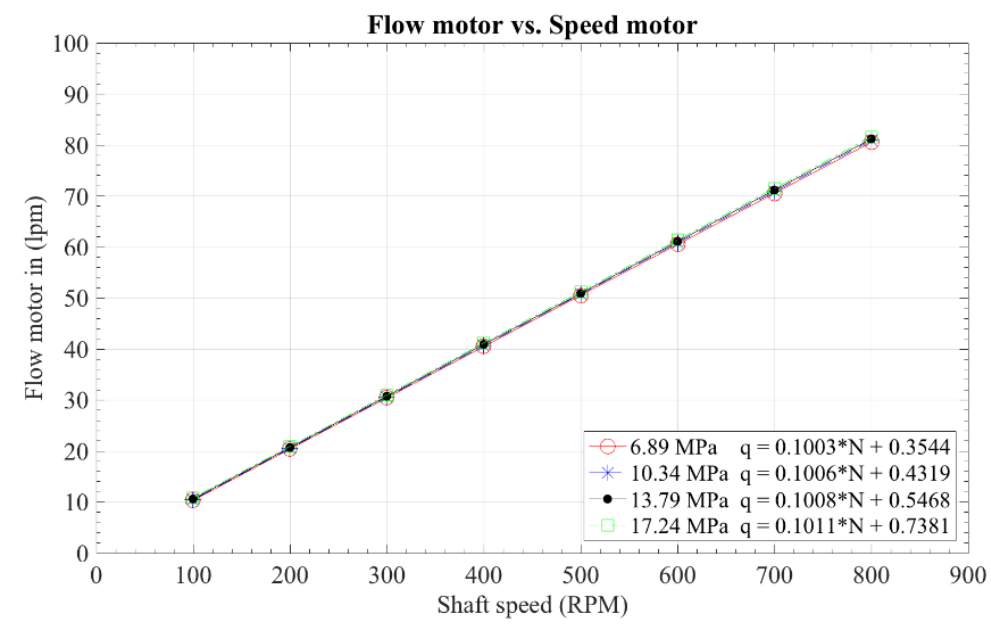

Figure 5: Step 1 of the Toet method; plot of axial piston motor inlet flow rate versus speed at four different pressures.

The second step in the Toet analysis is to plot slope versus pressure. When displayed this way, the slope of the line is in units of liters/MPa while the zero intercept is the derived displacement in liters/revolution. The derived displacement was $99.74 \mathrm{cc} / \mathrm{rev}$. The data exhibited good linearity with an $\mathrm{R}^{2}$ value of 0.994 . An $\mathrm{R}^{2}$ value of 0.994 means that $99.4 \%$ variation in the regression equation derived from the data can be accounted for by motor displacement and the incremental leakage flow per MPa. The pressure driven leakage flow rate was less than 0.2 $\mathrm{cc} / \mathrm{MPa}$.

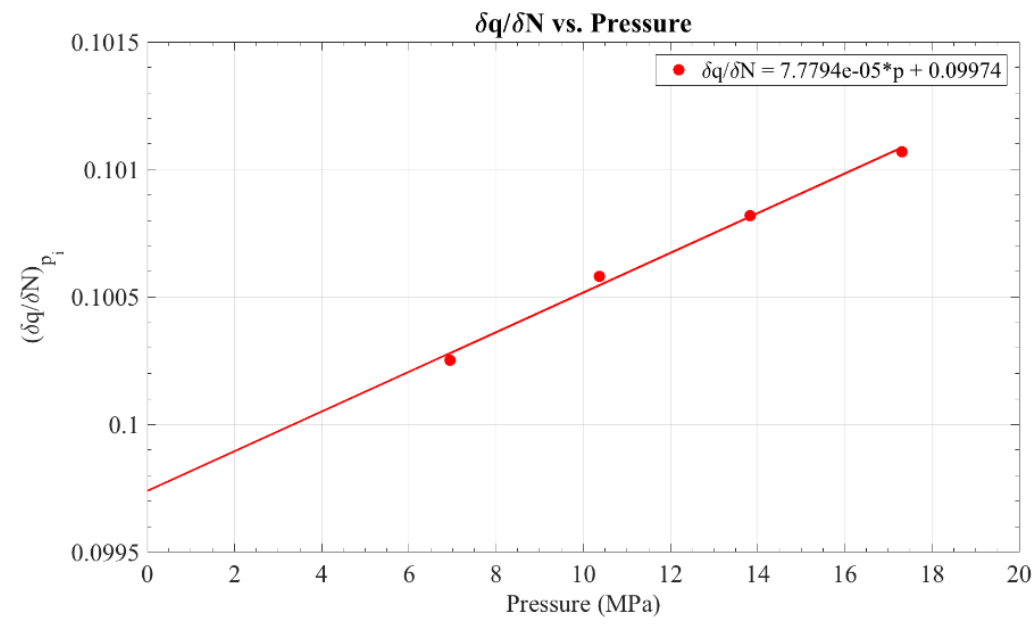

Figure 6: Step 2 of the Toet method; plot of the slope of flow with respect to speed versus pressure measurements for the axial piston motor.

The results of the derived displacement determination for the axial piston motor via the Wilson method are shown in fig. 7 and fig. 8. In fig. 7, plots of the motor inlet flow rate versus pressure are shown for eight different rotational frequencies. 


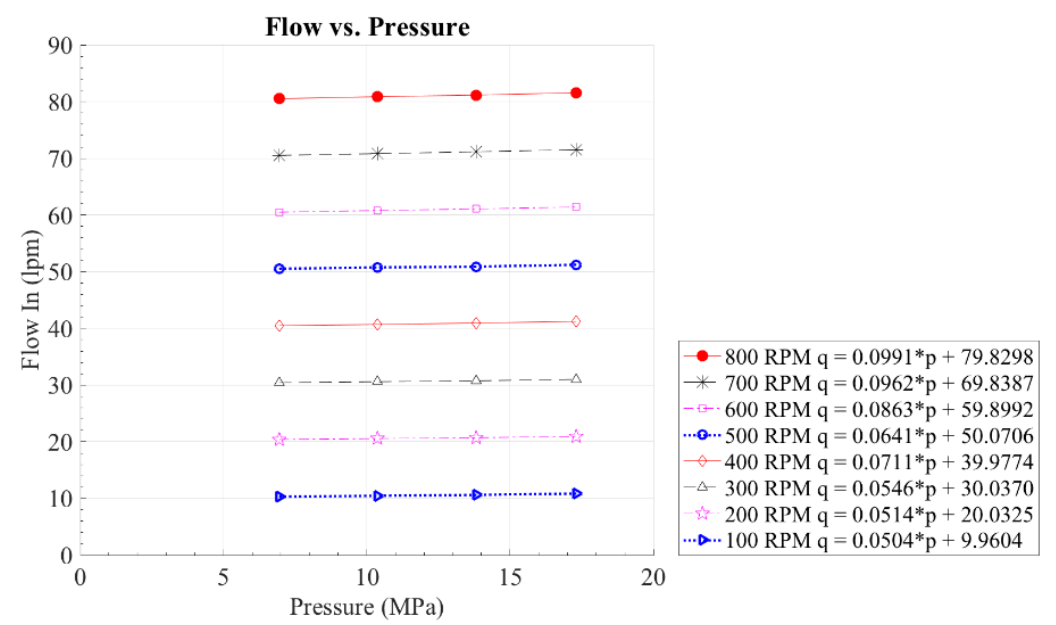

Figure 7: Step 1 of the Wilson method; plot of inlet flow rate versus pressure at four different pressures for the axial piston motor.

As can be seen from the regression equations, the pressure-driven leakage flow rate coefficient increased linearly as the speed was stepped up. The zero intercept values were a distinct function of the rotational frequency as expected.

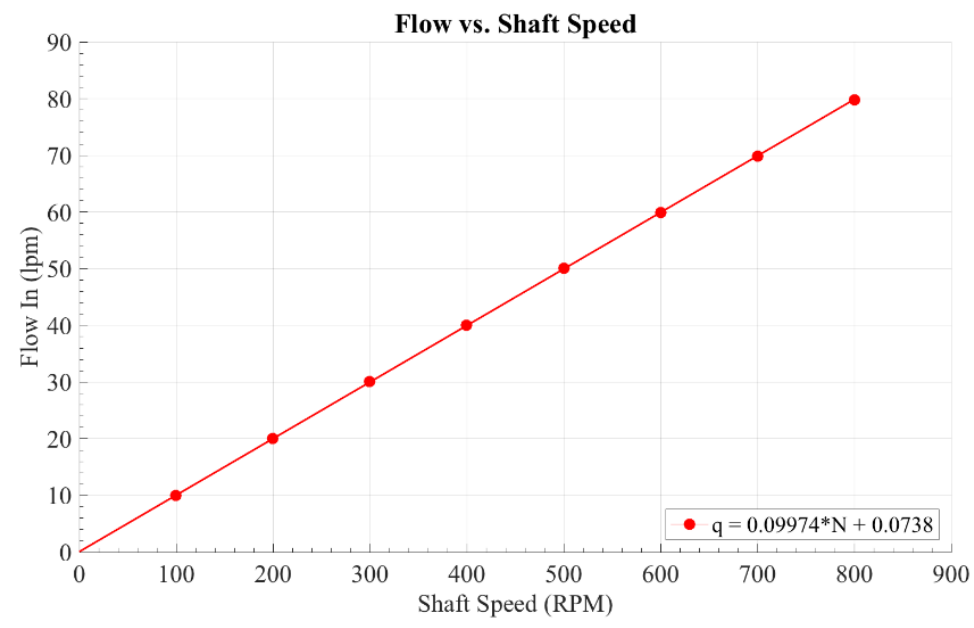

Figure 8: Step 2 of the Wilson method; plot of the flow versus speed measurements for the axial piston motor.

The second step in the Wilson method is to plot the intercept versus shaft speed as shown in fig. 8. The slope of the regression line is the displacement per revolution. As with the Toet method, the motor displacement was 99.74 cc per revolution. Since the Toet and Wilson methods used the same data, equal values for derived displacement were expected.

The orthogonal data that was used in the Toet and Wilson determinations was evaluated using multiple linear regression, (hereafter referred to as the One-step Toet method). The use of multiple linear regression to model experimental data assumes that there is a linear relationship between the independent and dependent variables, that the residuals are normally distributed, and that multicollinearity is absent. Equation 5 was used in the regression analysis.

The resulting ANOVA analysis for the One-step Toet method is shown in tab. 2. The motor inlet effective flow rate $\left(q_{v_{e}}\right)$ was the dependent variable in the equation. Thus, the constant term $\beta_{o}$ was determined to have units of cubic centimeters per minute (cc/min). The estimated value of $\beta_{o}$ was $75.1 \mathrm{cc} / \mathrm{min}$ with a standard error of 55.3 $\mathrm{cc} / \mathrm{min}$ and a $\mathrm{p}$-value of 0.186 . Since the $\mathrm{p}$-value is greater than 0.05 , the relationship between $\beta_{o}$ and the motor inlet flow rate is not statistically significant at a $95 \%$ confidence level. Essentially this means that the constant term could be omitted from the regression equation without negatively affecting the model integrity. In order to maintain mathematical equivalence to the graphical Toet method, it was necessary to include the constant term. 
With respect to determining derived displacement, the coefficient $\beta_{2}$ is the key value. $\beta_{2}$ is in units of volume per revolution and as can be seen in tab. 2, the estimated derived displacement of the motor was found to be 99.74 $\mathrm{cc} / \mathrm{rev}$. Hence the determination of the derived displacement using this method yielded the same results as the graphical Toet and Wilson methods up to four significant figures. The standard error of the derived displacement $V_{i}$, which is equivalent to the standard error of the $\beta_{2}$ coefficient, was $0.11 \mathrm{cc} / \mathrm{rev}$. To put this in perspective, the average volume of one droplet of hydraulic fluid at $50^{\circ} \mathrm{C}$ is 0.03 cubic centimeters. $0.11 \mathrm{cc} / \mathrm{rev}$ is less than 4 droplets of oil per revolution. The coefficient $\beta_{1}$ corresponds to a pressure dependent leakage flow coefficient. Hence the pressure-driven leakage flow rate was found to be $36.7 \mathrm{cc} / \mathrm{MPa}$ per minute. Unlike in a hydraulic pump, this leakage term is positive because the internal flow losses of a motor increase the inlet flow rate. The constant $\beta_{3}$ is in units of displacement over pressure. While the (Variance Inflator Factor) VIF for the $N^{*} p$ term was high, the physics and mathematics of determining derived displacement demand inclusion of this term in the flow model. The correlation coefficient $\left(\mathrm{R}^{2}\right)$ of the regression equation was $>99.99 \%$ with a Standard Error (SE) $43.3 \mathrm{cc} / \mathrm{min}$. Using linear regression to determine the derived displacement from the orthogonal data yielded the same results as the two-step graphical Toet and Wilson methods, with the advantage of generating an analysis of variance (ANOVA) for estimating the uncertainty of the derived displacement values.

Table 2: ANOVA analysis for the axial piston motor displacement determination base on linear regression of orthogonal test data (One-Step Toet Method).

\begin{tabular}{lcrrrr}
\hline Term & Symbol & Coeff. & SE Coeff. & p-Value & VIF \\
\hline Constant & $\beta_{o}$ & 75.1 & 55.3 & 0.186 & \\
Derived displacement, cc/rev & $\beta_{2}$ & $\mathbf{9 9 . 7 4}$ & $\mathbf{0 . 1 1}$ & 0.000 & 10.78 \\
Leakage flow coefficient & $\beta_{1}$ & 36.7 & 4.37 & 0.000 & 4.86 \\
$\mathrm{~N}^{*}$ p coefficient & $\beta_{3}$ & 0.078 & 0.009 & 0.000 & 14.64 \\
Coefficient of Determination & $\mathrm{R}^{2}$ & $>99.99 \%$ & & & \\
Standard Error & $\mathrm{SE}$ & $43.3 \mathrm{cc} / \mathrm{min}$ & & & \\
\hline
\end{tabular}

\section{Latin Hypercube sampling}

In a previous investigation we found that the Latin Hypercube sampling method yielded higher fidelity torque and flow models than orthogonal sampling [13]. Test points were selected using the Latin Hypercube Sampling (LHS) procedure. The LHS data set covered a higher range of operating speeds and pressures. (This data was collected to develop motor flow and torque models for system simulation.) Non-orthogonal LHS data sets were evaluated using multiple linear regression per eq. 5. The ANOVA results are shown in tab. 3 . Unlike the preceding orthogonal data, the $\mathrm{p}$-value for the constant term $\beta_{o}$ was less than 0.05 and there is a statistically significant association between the $\beta_{o}$ and the motor inlet flow rate at a $95 \%$ confidence level. The derived displacement $\beta_{2}$ obtained from the LHS data was $99.73 \mathrm{cc} / \mathrm{rev}$. This value was $0.01 \mathrm{cc} / \mathrm{rev}$ lower than that obtained from the orthogonal data. The standard error was also $0.01 \mathrm{cc} / \mathrm{rev}$ lower $(0.10 \mathrm{cc} / \mathrm{rev}$ vs. $0.11 \mathrm{cc} / \mathrm{rev})$. Since the sum of the products of the coefficient standard error $\left(S E_{c o e f}\right)$ and critical $t$ value $\left(t^{*}\right)$ for each method is greater than the difference between the LHS and One-step Toet derived displacements, the null hypothesis is not rejected. The relationship $S E, t^{*}$ and $C I$ is shown in eqn. 7 and eqn. 8 below. Thus, the difference between the results produced by the two methods (LHS and One-step Toet) was not statistically significant.

$$
\begin{gathered}
{\left[\left(\mathrm{SE}_{\text {Toet }}\right)\left(\mathrm{t}^{*}{ }_{\text {Toet }}\right)+\left(\mathrm{SE}_{\mathrm{LHS}}\right)\left(\mathrm{t}_{\text {LHS }}\right)\right]>\left|\mathrm{V}_{\text {iToet }}-\mathrm{V}_{\text {iLHS }}\right|} \\
\mathrm{CI}_{\text {Toet }}+\mathrm{CI}_{\text {LHS }}>\left|\mathrm{V}_{\text {iToet }}-\mathrm{V}_{\text {iLHS }}\right|
\end{gathered}
$$


Table 3: ANOVA analysis for the axial piston motor displacement determination base on linear regression of Latin Hypercube data over a wider range of pressures and speeds.

\begin{tabular}{lccrrr}
\hline Term & Symbol & Coef. & SE Coef. & p-Value & VIF \\
\hline Constant & $\beta_{0}$ & 240.7 & 728.2 & 0.004 & \\
Speed motor, RPM & $\beta_{2}$ & $\mathbf{9 9 . 7 3}$ & $\mathbf{0 . 1 0}$ & 0.000 & 9.91 \\
Leakage flow coefficient & $\beta_{1}$ & 34.52 & 4.56 & 0.000 & 4.55 \\
$\mathrm{~N}^{*}$ p coefficient & $\beta_{3}$ & 0.078 & 0.006 & 0.000 & 14.42 \\
Coefficient of Determination & $\mathrm{R}^{2}$ & $>99.99 \%$ & & & \\
Standard Error & $\mathrm{SE}$ & $84.6 \mathrm{cc} / \mathrm{min}$ & & & \\
\hline
\end{tabular}

The above analysis of the LHS data included a wider range of speeds and pressures than was used to collect the orthogonal data as indicated by the red squares in fig. 4. The question arises, would LHS data from the same hyperspace as the orthogonal data yield the same results? In a previous investigation, Johnson reported that it is advantageous to include the hyperspace vertices when analyzing LHS data [14]. The hyperspace vertices for the axial piston motor corresponded to 50 and $800 \mathrm{RPM}$, and 6.895 and $17.24 \mathrm{MPa}$. The ANOVA for the LHS hyperspace data with vertices is shown in Table 4 . The results indicate that the displacement $(99.82 \mathrm{cc} / \mathrm{rev})$ differs from the One-step Toet results by $0.08 \mathrm{cc} / \mathrm{rev}$. Since the difference between the LHS hyperspace and One-step Toet derived displacements was less than the sum of the products of $\left(S E_{c o e f}\right)$ and $\left(t^{*}\right)$ for each method, the null hypothesis is not rejected. In other words, the difference between the results produced by the two methods (LHS hyperspace and One-step Toet) was not statistically significant.

Table 4: ANOVA analysis for the axial piston motor displacement determination base on linear regression of Latin Hypercube data in the same hyperspace as the orthogonal data, including vertices.

\begin{tabular}{lccrrr}
\hline Term & Symbol & Coef. & SE Coef. & p-Value & VIF \\
\hline Constant & $\beta_{0}$ & 205.0 & 156.0 & 0.214 & \\
Speed motor, RPM & $\beta_{2}$ & $\mathbf{9 9 . 8 2}$ & $\mathbf{0 . 2 9}$ & 0.000 & 10.04 \\
Leakage flow coefficient & $\beta_{1}$ & 31.1 & 12.1 & 0.025 & 3.52 \\
N*p coefficient & $\beta_{3}$ & 0.075 & 0.023 & 0.006 & 11.91 \\
Coefficient of Determination & $\mathrm{R}^{2}$ & $>99.99 \%$ & & & \\
Standard Error & $\mathrm{SE}$ & $120.7 \mathrm{cc} / \mathrm{min}$ & & & \\
\hline
\end{tabular}

For the ISO 8426:2008 standard test method, the motor inlet flow rate was measured as a function of pressure at constant speed, temperature, and commanded displacement. Eleven measurements were collected using this method and the motor displacement value was calculated to be $98.72 \mathrm{cc} / \mathrm{rev}$ as shown in fig. 9 . The results indicate that the displacement differs from the orthogonal results by $1.02 \mathrm{cc} / \mathrm{rev}$. The $S E_{\text {coef }}$ for the ISO 8426:2008 method was smaller than the $S E_{\text {coef }}$ for the One-step Toet method. $(0.01 \mathrm{cc} / \mathrm{rev}$ versus $0.11 \mathrm{cc} / \mathrm{rev})$. The $t^{*}$ for the ISO 8426:2008 method was 2.262. The $t^{*}$ for the One-step Toet method was 2.048. Since the sum of the products of $S E_{c o e f}$ and $t^{*}$ for each method was less than the difference between the One-step Toet and ISO 8426:2008 displacement determinations, the null hypothesis was rejected. In other words, the difference between the Onestep Toet and the ISO 8426:2008 method was statistically significant in the axial piston motor. 


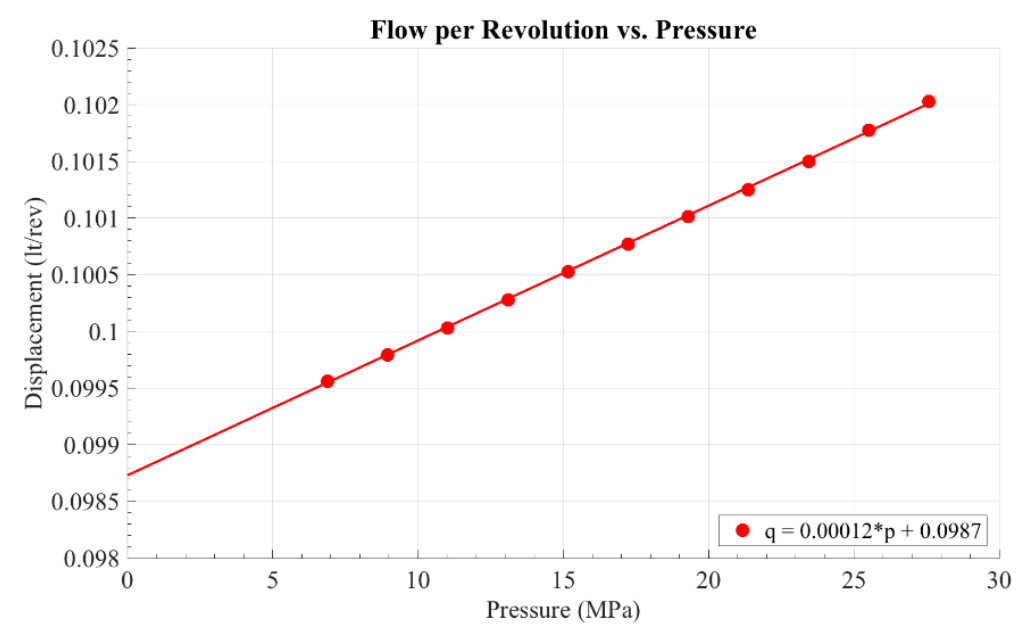

Figure 9: Plot of the flow per revolution versus pressure for the axial piston motor as specified in the ISO 8426:2008 method.

A comparison of the results for the different methods for determining the derived displacement is shown in fig. 10. Error bars illustrate the $95 \%$ confidence intervals for each data set from the axial piston motor. The graphical Toet and Wilson methods are not included because they yield the same results as the One-step Toet method but do not provide an error estimate. The differences in the derived displacement were not statistically significant in three out of four methods. The only method that generated a different derived displacement was ISO 8426:2008. The ISO 8426:2008 was 1\% lower, which means that based upon the ISO 8426:2008 displacement, the theoretical torque output of the motor would also be $1 \%$ lower. As has been noted elsewhere, this can lead to efficiency determinations greater than 100\% [5]. It has been hypothesized that discrepancies in ISO 8426:2008 results are due to speed-dependent cross-port leakage effects [16]. It should be noted that the $95 \%$ confidence interval for the ISO 8426:2008 method was narrower than that of the other methods. This is an artifact of measuring flow at a single speed; the resulting measurement yielded a narrow range of flow rates which obscured variations in the flow meter precision and motor speed control. Hence, collection of data points at multiple speeds is advantageous when determining the derived displacement.

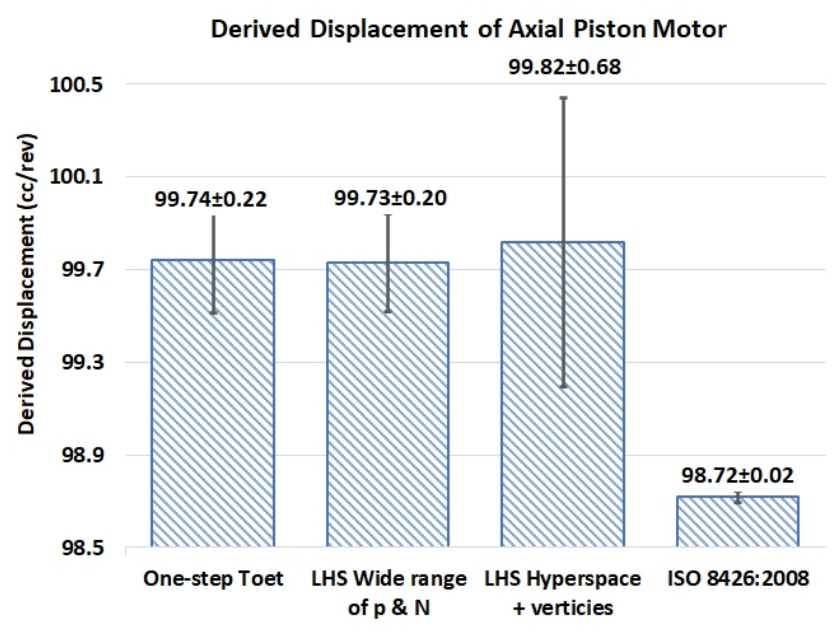

Figure 10: Results of the derived displacement of axial piston motor for the various methods tested.

As mentioned above, ISO 8426 displacement was $1 \%$ lower, and the difference was statistically significant at a 95\% confidence level. More importantly than quantifying how different these methods are, it seems appropriate to determine which method yields a more accurate result. As mentioned earlier, it is not possible to directly measure derived displacement. However, the examination of the efficiency results for the motor can provide insights regarding the accuracy of the method for determining the derived displacement. Fig. 11 below shows a plot of mechanical efficiency versus volumetric efficiency for the ISO 8426:2008 derived displacement results (left), and the Toet method (right). Note that the ISO method yielded mechanical efficiency results above $100 \%$ for low values of volumetric efficiency. This is a consequence of underestimating the derived displacement of a motor where volumetric efficiency, which has $V_{i}$ in the denominator, is underestimated, and mechanical efficiency, 
which has $V_{i}$ in the numerator, is overestimated. Efficiency results greater than $100 \%$ contradict first physics principles yet, have been reported in the literature by previous authors [4]-[6]. Hence the reader is invited to value the importance of accurately evaluating the derived displacement of pumps and motors so that accurate estimates of power loss and energy consumption may be reported.
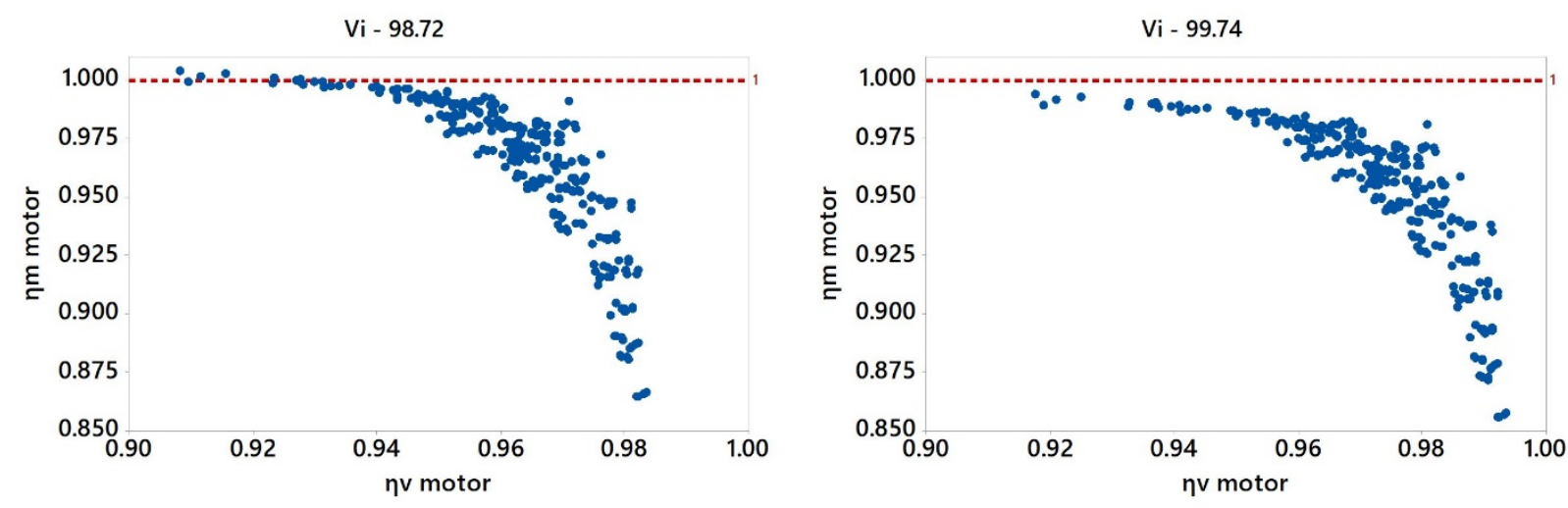

Figure 11: Mechanical and volumetric efficiencies of the axial piston motor based upon derived displacement via the ISO 8426:2008 method (left) and Tout method (right). Note that mechanical efficiency exceeded 100\% when using the ISO 8426:2008 method.

\subsection{Radial piston motor}

The test plan for the radial piston motor is shown in fig. 12. The pressure ranged from 6.89 to $27.58 \mathrm{MPa}$ and speed ranged from 50 to $564 \mathrm{RPM}$. Eleven measurements were collected between 6.89 to $27.58 \mathrm{MPa}$ at $500 \mathrm{RPM}$. Forty-six semi-randomized data points were collected for the Latin Hypercube Sampling method. Thirty-two orthogonal data points were collected for the Toet and Wilson methods (4 pressures and 8 speeds). Hence 89 data points were collected for the radial piston motor.

Test Points for Radial Piston Motor

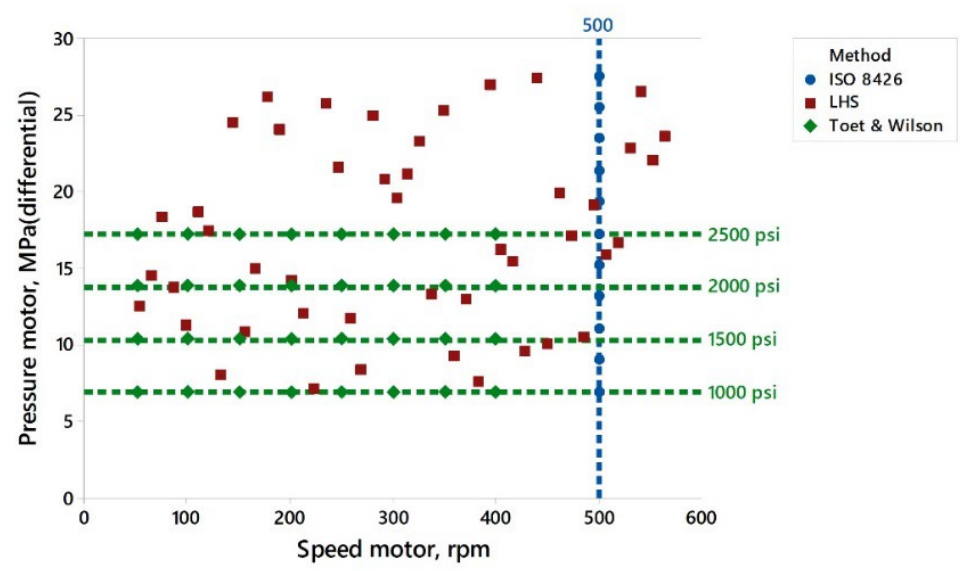

Figure 12: Test points for evaluating the derived displacement of the radial piston motor via ISO 8426:2008, Toet and Latin Hypercube methods.

The derived displacement for the radial piston motor was determined using the methods described in section 2 . A summary of the results is shown in fig. 13. The Wilson and Toet methods yielded a derived displacement of 211.82 cc/rev. Likewise, the One-step Toet method yielded $211.82 \mathrm{cc} / \mathrm{rev}$. The standard error for the displacement coefficient $\left(\beta_{2}\right)$ was $0.20 \mathrm{cc} / \mathrm{rev}$. The $\left(t^{*}\right)$ for a two-tailed $\alpha=0.05$ was 2.05 . Hence the $95 \% \mathrm{CI}$ for the One-step Toet method was $\pm 0.40 \mathrm{cc} / \mathrm{rev}$. The ISO 8426:2008 method produced a derived displacement of $211.49 \mathrm{cc} / \mathrm{rev}$ with a $95 \%$ CI of $\pm 0.17 \mathrm{cc} / \mathrm{rev}$. The net difference between the ISO 8426:2008 and Toet method was $0.33 \mathrm{cc} / \mathrm{rev}$. The sum of the confidence intervals was $0.47 \mathrm{cc} / \mathrm{rev}$. Since the difference between the displacement values was less than the CI, the disparity between the One-step Toet and ISO 8426:2008 methods was not statistically significant. The LHS hyperspace plus vertices data yielded similar results to the One-step Toet and ISO 8426:2008 methods. The LHS data from a wider range of pressures and speeds yielded a derived displacement that was 0.94 
cc/rev higher than that of the ISO 8426:2008 method. The sum of the confidence intervals for the two methods was $0.97 \mathrm{cc} / \mathrm{rev}$. Therefore, the null hypothesis was not rejected and the difference in the derived displacement measurements was not significant in the radial piston motor.

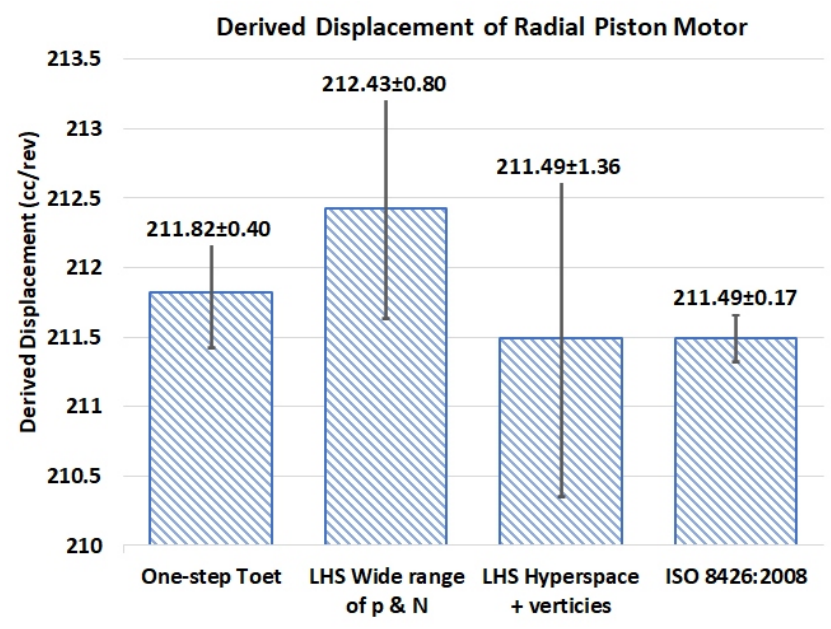

Figure 13: Results of the derived displacement of radial piston motor for the various methods tested.

\subsection{Variable displacement axial piston motor}

The test plan for the variable displacement motor is shown in fig. 14. The pressure ranged from 6.89 to 27.58 MPa and speed ranged from 50 to 1285 RPM. Eleven measurements were collected between 6.89 to $27.58 \mathrm{MPa}$ at 400 RPM and 1000 RPM to determine the derived displacement at the minimum and maximum swashplate angle. Forty-five non-orthogonal data points were collected for the One-step Latin Hypercube method. Twenty-four orthogonal data points were collected for the Toet and Wilson methods (4 pressures and 6 speeds). Hence 91 data points were collected for the variable displacement motor.

In the following analysis, full and partial displacements were determined from a single data set. The LHS hyperspace with vertices data set had only 6 degrees of freedom at partial displacement and 5 degrees of freedom at full displacement. Consequently, the coefficient $S E$ and $t^{*}$ values were high, resulting in confidence intervals of $\pm 5 \mathrm{cc} / \mathrm{rev}$ and $\pm 10 \mathrm{cc} / \mathrm{rev}$ at minimum and maximum displacement respectively. LHS hyperspace results are not included below because the required scaling would obscure meaningful differences in the other derived displacement methods.

Test Points for Variable Displacement Motor

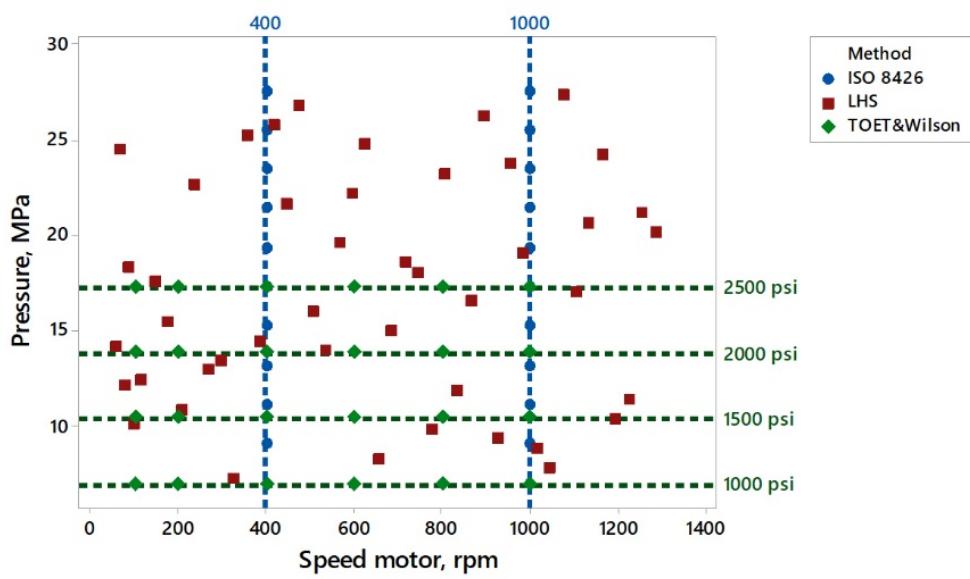

Figure 14: Test points for evaluating the derived displacement of the variable displacement motor via ISO 8426:2008, Toet and Latin Hypercube methods. 


\subsubsection{Variable motor partial displacement (high speed)}

The derived displacement of the variable displacement motor was evaluated using the methods described in Section 2. A summary of the partial- and full-displacement results is shown in fig. 15. The high-speed One-step Toet and ISO 8426:2008 displacements were 38.49 and $38.56 \mathrm{cc} / \mathrm{rev}$ respectively. The difference was $0.07 \mathrm{cc} / \mathrm{rev}$ while the CI for the methods was $\pm 0.29 \mathrm{cc} / \mathrm{rev}$. Since the One-step Toet results differed from the ISO 8426:2008 results by less than the CI, the two methods did not yield a statistically significant difference. Likewise, the LHS data from a wider range of pressures did not show a statistically significant difference in derived displacement values at high speeds.

\subsubsection{Variable motor full displacement (low speed)}

The One-step Toet and ISO 8426:2008 derived displacements ranged from 138.6 to $138.9 \mathrm{cc} / \mathrm{rev}$. Since the $95 \%$ CI for the One-step Toet included the ISO 8426:2008 result, these two methods cannot be said to produce a statistically significant difference in derived displacement. The LHS data at a higher range of pressures yielded a displacement of $137.9 \mathrm{cc} / \mathrm{rev}$ with a CI of $\pm 0.38 \mathrm{cc} / \mathrm{rev}$. The difference between the LHS and the ISO 8426:2008 derived displacement appears to be statistically significant. Non-linear changes in gap flow at high pressures may be a factor in the lower derived displacement value produced by the LHS data set. Alternatively, the narrow CI of the 8426:2008 method may be an underestimate of $S E_{\text {coef. }}$. When one considers that the ISO 8426:2008 confidence interval represents less than $0.06 \%$ of the derived displacement, the possibility that this method underestimates $S E_{\text {coef }}$ seems plausible.

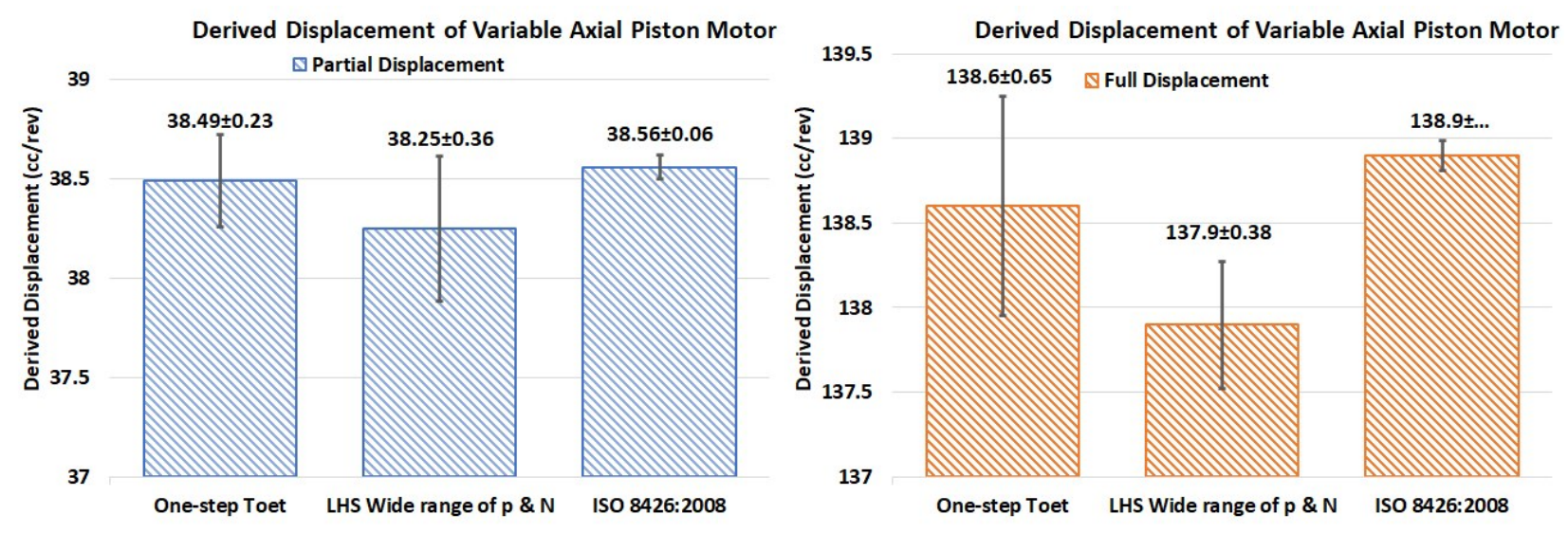

Figure 15: Results of the derived displacement of variable axial piston motor for the various methods tested.

\subsection{Temperature Effects}

The ISO 8426:2008 method was only investigated for pump inlet temperatures of $50^{\circ} \mathrm{C}$. The ISO 8426:2008 method was not evaluated at other temperatures. However, the effects of temperature and viscosity on derived displacement were investigated using LHS data from a wide range of pressures and speeds at $50^{\circ} \mathrm{C}$ and $80^{\circ} \mathrm{C}$. The two ISO VG 46 fluids described in tab 5 were compared. (Up to this point all of the derived displacement tests have been based upon Fluid "A" at $50^{\circ} \mathrm{C}$.) Fluids "A" and "B" had a viscosity index above 140 and therefore are categorized as ISO HV46 oils in the ISO 6743-4 classification system. Fluid "A" was on the low range of this standard, both in terms of kinematic viscosity at $40^{\circ} \mathrm{C}$ and viscosity index. Fluid "B" had a midrange viscosity at $40^{\circ} \mathrm{C}$ and a relatively high viscosity index. As shown in tab. 5, the fluids differed in density as well. This is due to a difference in base oil composition. From the perspective of an oil formulator, these fluids would be substantially different in cost and quality. However, it should be noted that the dynamic viscosities of the fluids at $50^{\circ} \mathrm{C}$ and $80^{\circ} \mathrm{C}$ (shown in bold type) are quite similar. 
Table 5: Properties of hydraulic fluids

\begin{tabular}{lcc}
\hline Hydraulic Fluid & A & B \\
\hline Kinematic Viscosity at $40^{\circ} \mathrm{C}, \mathrm{cSt}$ & 41.8 & 46.0 \\
Kinematic Viscosity at $100^{\circ} \mathrm{C}, \mathrm{cSt}$ & 7.23 & 8.70 \\
Viscosity Index & 142 & 170 \\
Density at $15^{\circ} \mathrm{C}, \mathrm{g} / \mathrm{cc}$ & 0.867 & 0.832 \\
Coefficient of Thermal Expansion, $/{ }^{\circ} \mathrm{C}$ & 0.000687 & 0.000728 \\
Dynamic Viscosity at $50^{\circ} \mathrm{C}, \mathrm{cP}($ calc. & $\mathbf{2 3 . 9}$ & $\mathbf{2 5 . 9}$ \\
Dynamic Viscosity at $80^{\circ} \mathrm{C}, \mathrm{cP}$ (calc.) & $\mathbf{9 . 4}$ & $\mathbf{1 0 . 6}$ \\
\hline
\end{tabular}

In the analysis below, data from the axial and radial piston motors was used to probe for the effects of temperature and fluid selection on derived displacement. The variable displacement motor was not evaluated in this stage because it was evaluated at two displacements, which effectively reduced the number of LHS data points to draw from by half.

The axial and radial piston motor LHS data from a wider range of pressures and speeds (red symbols in fig. 4 and fig. 12) was evaluated using eq. 5 . As shown in fig. 16a, displacement of the axial piston motor ranged from 99.78 cc/rev to $100.06 \mathrm{cc} / \mathrm{rev}$. Fluid "A" at $50^{\circ} \mathrm{C}$ produced the lowest derived displacement and Fluid "B" at $80^{\circ} \mathrm{C}$ produced the highest derived displacement result. The difference between these measurements was $0.28 \mathrm{cc} / \mathrm{rev}$ or less than $0.3 \%$. The sum of the $95 \%$ confidence intervals was $0.27 \mathrm{cc} / \mathrm{rev}$. Since the data spread and confidence intervals are nearly equal, the authors are hesitant to draw conclusions about the statistical significance of the difference between the derived displacement of Fluid " $\mathrm{A}$ " at $50^{\circ} \mathrm{C}$ and the derived displacement of Fluid "B" at $80^{\circ} \mathrm{C}$ in the axial piston motor. However it is clear that for a given fluid, the differences between the $50^{\circ} \mathrm{C}$ and $80^{\circ} \mathrm{C}$ results were not statistically significant.

Likewise, LHS data for the radial piston motor was evaluated via eq. 5. As shown in fig. 16b, the derived displacement of the radial piston motor ranged from $211.87 \mathrm{cc} / \mathrm{rev}$ to $212.30 \mathrm{cc} / \mathrm{rev}$. The difference was $0.43 \mathrm{cc} / \mathrm{rev}$ or roughly $0.2 \%$. The sum of the $95 \%$ confidence intervals for the top and bottom derived displacement values was $0.77 \mathrm{cc} / \mathrm{rev}$. Since the span of the confidence interval was greater than the spread in the results, the null hypothesis is not rejected. In other words, varying the fluid temperature and composition did not produce a statistically significant change in the estimated derived displacement for the radial piston motor. These results show that the One-step Toet method provides a robust method for determining the derived displacement even when the fluid temperatures differ by $30^{\circ} \mathrm{C}$.
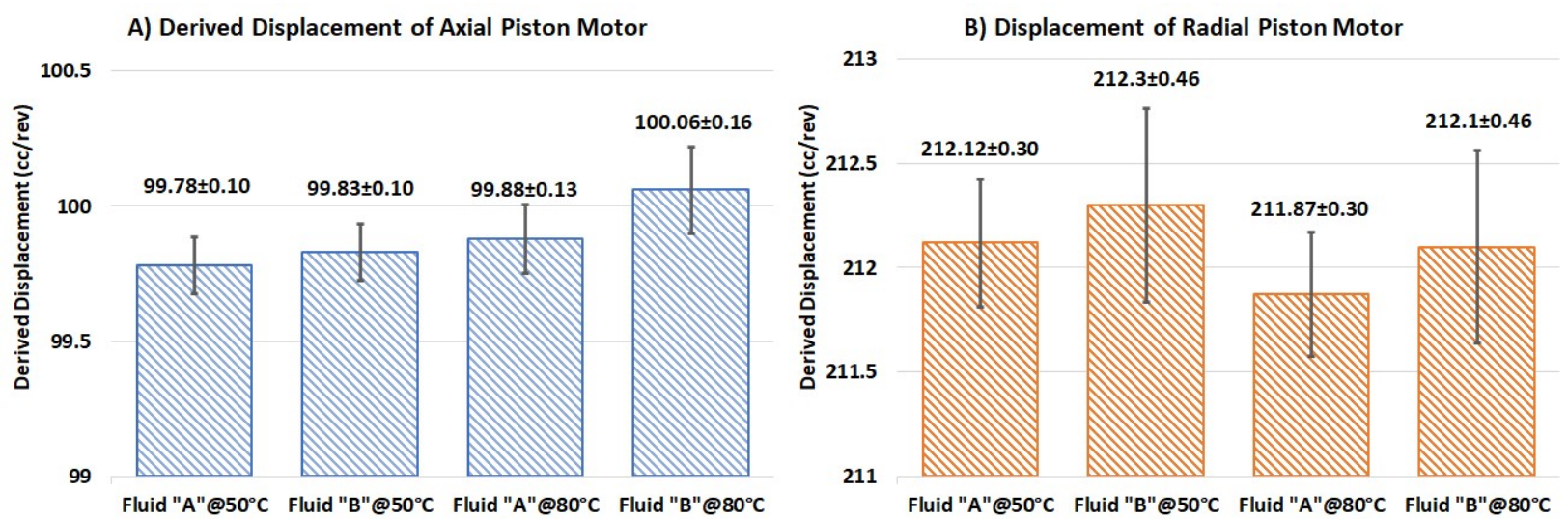

Figure 16: Comparison of derived displacement results for two fluids at $50^{\circ} \mathrm{C}$ and $80^{\circ} \mathrm{C}$ in the axial and radial piston motors.

\subsection{Viscosity Effects}

Gap flow or internal leakage in positive displacement machines is proportional to pressure and inversely proportional to viscosity [14]. Hence, it has been proposed that a viscosity term be used in the One-step Toet equation to account for this effect. In the analysis below, the dynamic viscosities of the fluids were used to determine if modifying the One-step Toet equation to include a viscosity term improves the fidelity of the derived 
displacement determination. The kinematic viscosities of the oils at the motor inlet temperature were calculated using the Walther equation. The density of the fluid at the motor inlet temperature was calculated using the coefficient of thermal expansion listed in the fluid property table. (The density was not pressure corrected.) The product of kinematic viscosity and density was used to convert to dynamic viscosity $(\mu)$ of the fluid. Finally, the term $p_{i} / \mu$ was used in place of $p_{i}$ in the modified One-step Toet equation as shown in eq. 9.

$$
q_{v_{e}}=\beta_{3} p_{i} N+\beta_{2} N+\beta_{1} p_{i} / \mu+\beta_{0}
$$

A comparison of the results in fig. 16a and 17a reveals that inclusion of the pressure/viscosity ratio had a minimal effect on the derived displacement in the axial piston motor $(<0.02 \mathrm{cc} / \mathrm{rev})$. The standard error was nearly unchanged as well. Likewise inclusion of the pressure/viscosity ratio had a minor impact on the derived displacement of the radial motor as shown in fig. $16 \mathrm{~b}$ and $17 \mathrm{~b}$. These results indicate that the inclusion of a viscosity term did not enhance the integrity of the derived displacement determination when individual fluid and temperature combinations are evaluated independently.
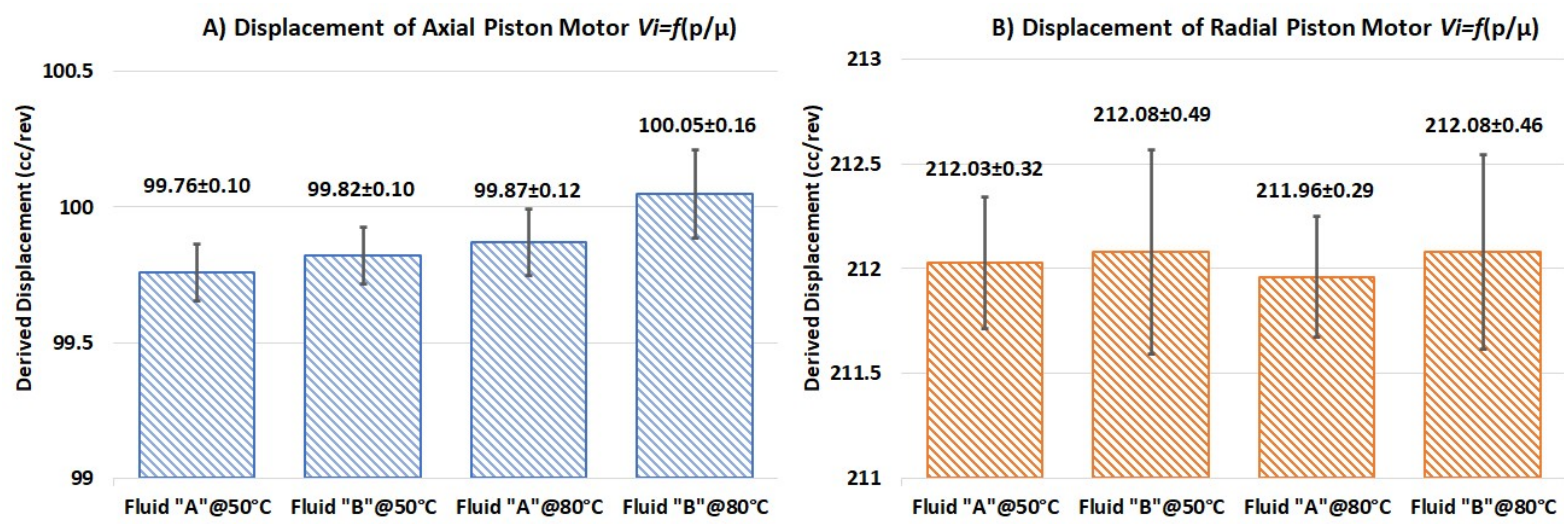

Figure 17: Derived displacement for axial piston (A) and radial piston motor (B) as a function of the viscosity/pressure ratio

\section{Summary and conclusions}

This paper examines alternative methods for determining hydraulic motor displacement and compares the results with the current ISO 8426:2008 procedure. Fixed axial piston, variable axial piston, and radial piston motors were evaluated at $50^{\circ} \mathrm{C}$ and $80^{\circ} \mathrm{C}$ in dynamometer tests. Linear, orthogonal, and semi-randomized data sets were collected. The linear (single speed) data was used to determine displacement via ISO 8426:2008. The orthogonal data (a matrix of pressures and speeds) was used to determine displacement using the Toet and Wilson methods. Displacement was determined from the Latin-Hypercube Semi-randomized (LHS) data by way of an analytical form of the Toet method. The analytical Toet method was derived to facilitate the estimation of uncertainty in the displacement using statistical software in a single step (One-step Toet). The One-stet Toet method was shown to produce results that are identical to the graphical Wilson and Toet methods.

In general, the differences between the various derived displacement methods were not statistically significant, except in the instance of the axial piston motor. In the axial piston motor, the ISO 8426:2008 derived displacement was approximately 1\% lower than the other methods. Use of the lower ISO 8426:2008 displacement value in mechanical efficiency calculations produced values exceeding 100\%. This phenomena has been reported in previous publications [4]-[6]. Underestimating the derived displacement of a motor skews mechanical efficiency high because $V_{i}$ is used to calculate theoretical torque, which is in the denominator of the mechanical efficiency equation. This did not occur using the other methods where displacement was determined at multiple speeds. The error in the ISO 8426:2008 derived displacement determination was attributed to difficulties in detecting speeddependent factors that affect displacement when testing is conducted at a single speed. The ISO 8426:2008 method does not prohibit testing at multiple speeds, nor does it provide instructions for calculating derived displacement when data is collected at more than one speed. The One-step Toet method produced consistent results for various combinations of pressures, speeds, fluids, and temperatures. It is proposed that the One-Step Toet method be incorporated into a revised version of ISO 8426 as the means for calculating the derived displacement when users opt to measure performance at multiple speeds. This modification will help reduce the potential for speeddependent errors in the determination of derived displacement. 


\section{Nomenclature}

\begin{tabular}{lcc}
\hline Property & Symbol & Units \\
\hline Shaft speed & $N$ & $\mathrm{rpm}$ \\
Pressure & $p$ & $\mathrm{MPa}$ \\
Differential pressure & $\Delta p$ & $\mathrm{MPa}$ \\
Derived Displacement & $V_{i}$ & $\mathrm{cc} / \mathrm{rev}$ \\
Geometric Displacement & $V_{g}$ & $\mathrm{cc} / \mathrm{rev}$ \\
Volumetric Flow Rate & $q_{v_{e}}$ & $\mathrm{~L} / \mathrm{min}$ \\
Dynamic Viscosity & $\mu$ & $\mathrm{Centipoise} \mathrm{(cP)}$ \\
Analysis of Variance & $A N O V A$ & \\
Linear Regression Coefficient & $\beta_{0,}, \beta_{1}, \beta_{2,}$ & \\
Confidence Interval & $C I$ & \\
Latin Hypercube Sampling & $L H S$ & \\
Correlation Coefficient & $R^{2}$ & \\
Standard Error of the Regression Coefficient & $S E_{c o e f}$ & \\
Critical t statistic & $t^{*}$ & \\
\hline
\end{tabular}

\section{Acknowledgments}

The authors gratefully acknowledge Shukai Zhang, graduate research assistant at Milwaukee School of Engineering, for collecting, processing, and organizing the experimental data used in this study.

\section{References}

[1] Love, L., Lanke, E., and Alles, P., "Estimating the Impact (Energy, Emissions and Economics) of the U.S. Fluid Power Industry," Oak Ridge National Laboratory: Report No.:ORNL/TM-2011/14. (2012)

[2] Achten, P., Mommers, R., Nishiumi, T., Murrenhoff, H., Sepehri, N., Stelson, K., ... \& Schmitz, K. (2019). Measuring the losses of hydrostatic pumps and motors: A critical review of iso4409: 2007. In ASME/BATH 2019 Symposium on Fluid Power and Motion Control. American Society of Mechanical Engineers Digital Collection.

[3] Williams, L. T. (2020, September). Methodology for the Evaluation of Gear Pump Performance. In Fluid Power Systems Technology (Vol. 83754, p. V001T01A030). American Society of Mechanical Engineers.

[4] Williamson, C., and Manring, N. "A More Accurate Definition of Mechanical and Volumetric Efficiencies for Digital Displacement ${ }^{\circledR}$ Pumps.” In ASME/BATH 2019 Symposium on Fluid Power and Motion Control. ASME Digital Collection Paper FPMC2019-1668 (2019).

[5] Bramer, J. Puzzuoli, A. Michael, P. and Wanke, T. "Hydraulic Fluid Efficiency Effects in External Gear Pumps," Proceedings of the $53^{\text {rd }}$ National Conference on Fluid Power - National Fluid Power Association, Paper NCFP I14-13.3, Las Vegas, NV (2014) 
[6] Garcia-Bravo, J., Nicholson, J., "What is the real size of a pump? Revisions to ISO 8624: A standard for determination of the derived capacity of hydraulic pumps and motors", Fluid Power Journal Magazine, June 2018. Vol. 25 Issue (6), pp. 74-75.

[7] ISO 4391:1986. "Hydraulic fluid power - Positive displacement pumps, motors and integral transmissions Parameter definitions and letter symbols." International Organization for Standardization, Geneva, Switzerland (1986)

[8] Wilson, Warren Elvin. "Performance criteria for positive displacement pumps and fluid motors." Trans. ASME 71, no. 2: 115-120. (1949)

[9] Toet, G., "Die Bestimmung des theoretischen Hubvolumens von hydrostatischen Verdränger-pumpen und Motoren aus volumetrischen Messungen," Ölhydraulik und Pneumatik 14. Nr. 5, 185-190. (1970)

[10] Post, W. J. A. E. M., "Models for steady-state performance of hydraulic pumps: determination of displacement," In C. R. Burrows, \& K. A. Edge (Eds.), Fluid power systems: 9th international workshop, University of Bath, England, 9-11 September 1996 (pp. 339-353). (Fluid power series; Vol. 9). Chichester: Research Studies Press. (1997)

[11] ISO 8426:2008. "Hydraulic fluid power - Positive displacement pumps and motors - Determination of derived capacity." International Organization for Standardization, Geneva, Switzerland (2008).

[12] Toet, G., Johnson, J., Montague, J., Torres, K. and Garcia Bravo, J. "The Determination of the Theoretical Stroke Volume of Hydrostatic Positive Displacement Pumps and Motors from Volumetric Measurements." Energies, 12, 415 (2019).

[13] Panwar, P. and Michael, P., "Empirical Modelling of Hydraulic Pumps and Motors based upon the Latin Hypercube Sampling Method," International Journal of Hydromechatronics, Vol. 1, No. 3, pp.272-292 (2018)

[14] Johnson, J., "Design of experiments and progressively sequenced regression are combined to achieve minimum data sample size," International Journal of Hydromechatronics, 2018 Vol.1 No.3, pp.308 - 331 (2018)

[15] ISO 4409:2019 "Hydraulic fluid power - Positive-displacement pumps, motors and integral transmissions - Methods of testing and presenting basic steady state performance". International Organization for Standardization, Geneva, Switzerland (2019).

[16] Kim, T., Kalbfleisch, P. and Ivantysynova, M. "The effect of cross porting on derived displacement volume," International Journal of Fluid Power, 15:2, 77-85, (2014)

[17] Wilson, Warren. E., Positive Displacement Pumps and Fluid Motors, Pitman Publishing, NY, Chap. 6. (1950) 